\title{
The Role of Culture on Food Choices: A Case Study of Hospitality Clientele in Independent Commercial Catering Outlets
}

\author{
Mr. Simon Were Okwachi ${ }^{1}$, Dr. Moses Miricho ${ }^{1}$, Dr. Vincent Maranga ${ }^{1}$ \\ ${ }^{1}$ Kenyatta University, School of Hospitality and Tourism Management
}

*Corresponding Author: Mr. Simon Were Okwachi, Kenyatta University, School of Hospitality and Tourism Management

\begin{abstract}
The purpose of this paper is to find out the influence of cultural factors on food choices by hospitality clientele in independent commercial catering outlets within Kisumu County in Kenya. Data was collected from nine independent commercial catering outlets licensed by the Tourism Regulatory Authority, Western Kenya. The collected data include demographic information, cultural factors; traditions, taboos, beliefs and rituals. Linear regression was used to explore the relationship between the moderating effect of environmental factors on the relationship between cultural factors and food choices. The results of the study depicts majority of respondents indicated that food choices are determined by cultural factors; traditions, taboos, beliefs and rituals respectively. Consequently, the study results show that environmental factors have a moderating influence on the food choices by hospitality clientele. Due to financial and time constrains, this study does not capture all the dependent commercial catering outlets as well as both dependent and independent commercial catering outlets licensed by the county government of Kisumu, thus the findings may be applied with caution outside the scope of this study. Basing on the results of the study, hospitality professionals should factor in the cultural element during menu planning to strike a balance between the catering policy, the financial policy as well as the marketing policy. The research addresses the critical topic of cultural factors determining food choices, which seems to be evolving with time, hence complicating food and beverage business across the world.
\end{abstract}

Keywords: Cultural factors, environmental factors, food choices, hospitality clientele, ethnic cuisines, fusion cuisines, contemporary cuisines

\section{INTRODUCTION}

Food and culture are two different worlds that go very well together. When one grows up in a distinctive culture, it's bound to influence his/her lifestyle, including adopted traditions, taboos, rituals, belief system-and perhaps most enjoyable, his/her food choice (Lamb 2015). This means cultural factors remain fundamental in our daily food choice and consumption across the world, and thus it is true to say that hospitality clientele's food choice has been, and will remain to be as a result of the cultural determinants. Nonetheless, Lillicrap \& Cousins (2010) confirms that modern day food choices are as a result of a number of factors, including culture, and thus food choice diversity.

Cardan (2015) asserts that Food choices among the global hospitality clientele are diverse, including ethnic cuisines, fusion cuisines and contemporary cuisines, with a variety of factors determining these choices (Davies, Lockwood, Pantelichi \& Alcott, 2008). Nevertheless, in spite of this broad classification of cuisines, the menu, and especially the Kenyan menu, has particularly focused on exotic national cuisines such as the French cuisine, Italian cuisine, German cuisine, Mexican cuisine, Indian cuisine etc (Jee Hye Lee, 2014) in an effort to increase and/ or maintain profitability. On a global perspective, Carlson \& Frazao (2012) argues that although the most popular ethnic cuisines continues to be Italian, Chinese and Mexican, some of the global ethnic restaurants gaining ground in the recent years include Thai, Ethiopian and Indian. This is suggestive that some of the previously dominant global ethnic food choices are diminishing, just like the Kenyan ethnic foods, which is already extinct. And thus today, cultural proliferation, Mcdonaldization and Americanization (Cardan, 2015) has colonized not only the Kenyan but also the global Food and Beverage sector. This has been with the assumption that these cuisines are widely acceptable across the global hospitality market segment (Cardan, 2015), unlike the pure ethnic Kenyan cuisines. Thus it is common to find foods 
such as French fries, chicken ala' king, spaghetti cabonara, hollandaise sauce, sweet and sour sauce, chef's salad with French dressing etc. on the menu within the Kenyan catering outlets.

Moreover, the Kenyan hospitality training institutions have put more emphasis on culinary skills that incline towards the worlds' cuisines, with very little, and sometimes no focus on the pure ethnic culinary skills within their programs (Carlson et al., 2012). The resultant graduates, who forms the key industry players both locally and internationally (Cardan, 2015), ends up with vast knowledge on national cuisines from other countries and continents at the expense of their local Kenyan ethnic cuisines. The same has extended to the hospitality's world of academics, with publications of menus and recipe's favoring world exotic cuisines, which comprises an inter-mix of the world ingredients, hence producing world global cuisines (Wales, 2009) such as contemporary as well as fusion cuisines.

In view of the various food choices, Sims (2012) reiterates that the global hospitality industry has over-emphasized fusion and contemporary foods at the expense of pure ethnic cuisines, with Kenya being no exception. This has also been catalyzed by exposure of the current global hospitality clientele, as many are well travelled (Wessel \& Brien, 2010), and emigration is largely experienced across the world, thus breaking the Ethnic cuisines traditional borders.

Consequently, the coexistence of several ethnic groups, with their fading cultural characteristics (Elbert, 2011), has given rise to a variety of labels such as cultural diversity, cultural heterogeneity, multiculturalism and polyethnicity. All these has contributed to acculturation, assimilation, diffusion as well as adaptation (Stuart, 2008), which has significantly led to the total demise of ethnic food, as the same has greatly disrupted the original cultural factors that determine food choices.

In combination, these forces against Kenyan ethnic food choices has given birth to loss of authenticity of the ethnic menu, hence being overtaken and/ or replaced by fusion and contemporary foods (Jee Hye Lee, 2014), with the view of satisfying the current hospitality clientele's needs and preferences. Kenyan ethnic cuisines therefore not only have lost demand and profitability across the world (Stuart, 2008), but also recognition, which has brought about corresponding extinction. Thus in contrast with the expectations, the ethnic menu is unable to meet the specific objectives of the marketing policy, the catering policy as well as the financial policy (Lillicrap et al, 2010), due to the dwindling attractiveness of the cultural market segment.

\section{MATERIALS AND MeTHOdS}

A cross-sectional survey design, concerned with examining variation across cases (Henn, Weinstein \& Ford, 2009), as well as a descriptive correlation research survey, which allows the researcher to describe and evaluate the relationship between the study variables by asking questions to the respondents and examining their relationships were adopted. Eric, Alan, Shankar \& Christine (2008) asserts that cross-sectional research survey involves using different groups of people who differ in the variable of interest, which formed the dependent variable of the study (Food choice) but share other characteristics such as socioeconomic status, educational background, and ethnicity, which in this case formed the independent variable of the study. Consequently, descriptive correlation research design was instrumental in examining cultural variations of the hospitality clientele in the multiethnic, cosmopolitan Kisumu County, and was therefore chosen for its appropriateness in fact finding to yield accurate information (Kothari, 2010). Factors under investigation were cultural factors determining food choices as independent variable (IV), environmental factors as moderating variables (MV), while food choices formed the dependent variable (DV).

Kisumu, the principle port city of Western Kenya in Kisumu County, the immediate former capital of Nyanza province, covering 2,085.9KM ${ }^{2}$ with a population of 968,879 (2009 census) (Kisumu County, 2013), formed the area of study. Kisumu County's neighbors are: Siaya County to the West, Vihiga County to the North, Nandi County to the North East, and Kericho County to the East. Kisumu is the third largest city in Kenya, the second most important after Kampala in the greater Lake Victoria basin, characterized with pronounced cultural and ethnic diversity among the residents, on the forefront in eco-cultural tourism, a multi-ethnic, cosmopolitan, leading commercial trading, industrial administration and communication Centre in the lake basin region (Helen, Stephen, Alfred, Doris, Michael \& Charles, 2015), a key market as well as the gateway to the landlocked countries of East Africa. Thus Kisumu city was chosen because of her dense and ever swelling population at a growth rate of 2.1\%, comprising of multi-ethnic, cosmopolitan inhabitants (Helen et al, 2015), hence with a pronounced cultural and ethnic diversity, and specifically on food choices among the residents. 
The target population of the study constituted independent commercial catering food outlets with a specific focus on hospitality clientele, as well as managerial and/or supervisory staff within the independent commercial catering outlets in Kisumu County. For purposes of this study, nine (9) independent commercial catering outlets, licensed by the Tourism Regulatory Authority, Western Kenya, were chosen. Purposive sampling was adopted, mainly for the selection of commercial catering outlets from the study population of all the licensed catering outlets, systematic random sampling was used in the distribution of respondents among the nine independent commercial catering outlets, and thereafter simple random sampling was employed for the selection of respondents from each of the selected independent commercial catering outlets, with a sample size of 384 respondents.

Data was collected by use of two research instruments; a self administered questionnaire, a research instrument consisting of a series of questions and other prompts with the aim of gathering information from respondents (Kothari, 2010). For the purpose of this study, the questionnaire comprised both closed-ended as well as open ended questions (Henn et al, 2009), aiming at investigating food choices among hospitality clientele in Kisumu County. This allowed the respondents greater freedom of expression, in relation to the cultural factors determining food choices under investigation. The questionnaire comprised of seven sections, with the first section addressing demographic factors of the respondents, the second section investigated traditions (IV), the third section was on taboos (IV), the fourth was on beliefs (IV), the fifth on rituals (IV), the sixth section investigated food choices (DV), and finally the seventh was to establish the moderating effect of environmental factors (MV) on the relationship between cultural factors influence on food choices, thus addressed the study objective.

Consequently, the study employed open-ended one-to-one interviews in which individual respondents were questioned about a particular issue, experience or event (Henn et al, 2009). Qualitative semistructured/ unstructured interviews were conducted with the researcher's intention to explore the views, experiences, beliefs and motivations of individual respondents, (Gill, Stewart, Treasure, \& Chadwick, 2008.), hence allowing generation of qualitative data. In every independent commercial Catering outlet, there was one supervisory staff to which interviews were carried out.

Quantitative data collected from respondents was coded, fed into spreadsheets, and thereafter analyzed using SPSS version 20. The study used both descriptive and inferential statistics during data analysis. Open ended questions were qualitatively analyzed using the basis of the frequency of the responses, while numerical scores were awarded to closed ended questions. Descriptive statistics employed the use of frequencies and percentages, and for inferential statistics, regression was applied to determine the direction and find out whether there is influence of cultural factors on the relationship between hospitality clientele and food choices in independent commercial catering outlets within Kisumu County. Furthermore, chi square $\left(\chi^{2}\right)$ at $95 \%$ confidence level was used to test hypotheses as well ANOVA and t-test.

\section{RESUlTS AND DisCUSSIONS}

Data was coded and analyzed on the basis of demographic factors as well as cultural factors determining food choices. Consequently, the moderating effect of environmental factors on the relationship between cultural factors influence on food choices was established as discussed below;

\subsection{Demographic Factors}

The researcher obtained information about the personal data of respondents. The data was related to gender, marital status, age and monthly income. These factors are generally important in food choices by hospitality clientele, and thus relevant in this study. In order to obtain the data, a coded language was entered in a spreadsheet then the qualitative data was converted to quantitative data which could be understood by the researcher. The results were as presented below;

\subsubsection{Marital Status of Respondents}

Out of the 375 respondents, the results indicates that 243 respondents (64.8\%), were married, 121 respondents $(32.3 \%)$ were single and 11 respondents (2.9\%) were neither married nor single as shown in table 3.1. 
The Role of Culture on Food Choices: A Case Study of Hospitality Clientele in Independent Commercial Catering Outlets

Table3.1. Respondents Marital Status

\begin{tabular}{|c|c|c|c|}
\hline Variable & Frequency & Percent & Cumulative Percent \\
\hline Married & 243 & 64.8 & 64.8 \\
\hline Single & 121 & 32.3 & 97.1 \\
\hline Others & 11 & 2.9 & 100.0 \\
\hline Total & $\mathbf{3 7 5}$ & $\mathbf{1 0 0 . 0}$ & \\
\hline
\end{tabular}

\subsubsection{Age of Respondents}

The results obtained on the respondents' age were as shown in table 3.2. Among the respondents, the age groups $20-39$ years comprised of 214 respondents $(57.1 \%), 40$ years and above were 92 respondents $(24.5 \%)$, while $05-19$ years were 69 respondents $(18.4 \%)$.

Table3.2. Respondents Age

\begin{tabular}{|c|c|c|c|}
\hline Variable & Frequency & Percent & Cumulative Percent \\
\hline 05-19 Yrs. & 69 & 18.4 & 18.4 \\
\hline 20-39 Yrs. & 214 & 57.1 & 75.5 \\
\hline$>40$ & 92 & 24.5 & 100.0 \\
\hline Total & $\mathbf{3 7 5}$ & $\mathbf{1 0 0 . 0}$ & \\
\hline
\end{tabular}

\subsubsection{Respondents Gender}

The researcher also sought to find out the composition of respondents in terms of gender. The results were as shown in table 3.3. From the results in table 3.3 above, the respondents comprised of 217 (57.9\%) male respondents and 158 (42.1\%) female respondents

Table3.3. Respondents Gender

\begin{tabular}{|c|c|c|c|}
\hline Variable & Frequency & Percent & Cumulative Percent \\
\hline Male & 217 & 57.9 & 57.9 \\
\hline Female & 158 & 42.1 & 100 \\
\hline Total & $\mathbf{3 7 5}$ & $\mathbf{1 0 0 . 0}$ & \\
\hline
\end{tabular}

\subsubsection{Monthly Income of Respondents}

Monthly Income of the respondents was investigated and the results were shown in table 3.4 below. From table 3.4, the results show that 166 respondents (44.3\%) are earning between Ksh.30, 000 Ksh. 49,000, 107 respondents (28.5\%) are earning Ksh. 50,000 and above, and 102 respondents (27.2\%) are earning Ksh. 29,000 and below.

Table3.4. Respondents Monthly Income

\begin{tabular}{|l|c|c|c|}
\hline \multicolumn{1}{|c|}{ Variable } & Frequency & Percent & Cumulative Percent \\
\hline Ksh.29,000 And Below & 102 & 27.2 & 27.2 \\
\hline Ksh.30,000-Ksh.49,000 & 166 & 44.3 & 71.5 \\
\hline Ksh.50,000 And Above & 107 & 28.5 & 100.0 \\
\hline Total & $\mathbf{3 7 5}$ & $\mathbf{1 0 0 . 0}$ & \\
\hline
\end{tabular}

\subsection{The Role of Culture on Food Choices by Hospitality Clientele}

The study sought to establish the relationship between cultural factors and food choices among the independent commercial catering hospitality clientele within Kisumu County. These factors included traditions, taboos, beliefs, and rituals. Data was analyzed and the results discussed below;

\subsubsection{Traditions of Respondents}

Respondents were asked to indicate the extent to which the various factors under traditions determine their food choices; a likert scale was used to asses' the responses regarding the extent to which traditions influence food choices of the hospitality clientele, and the responses were analyzed and presented in table 3.5. From the results, nutritional requirements was ranked the highest with $21.9 \%$ of respondents who indicated that it determines food choices to a very large extent, $12.5 \%$ of respondents indicated religious dietary requirements determine food choices to a very large extent, and $12 \%$ indicated that nature of the food item determine food choices to a very large extent. On the 
other extreme, $39.9 \%$ of respondents indicated that food composition determines food choices to no extent at all, 33.3\% of respondents indicated that cultural dietary rules determine food choices to no extent at all, and $12.5 \%$ indicated that ethnic identity and religious dietary requirements determine food choice to no extent at all. From the results obtained, it shows that over eighty percent of food choices are made on the basis of traditions.

Table3.5. Likert Scale on Traditions in Relation to Food Choice

\begin{tabular}{|c|c|c|c|c|c|c|c|c|c|c|}
\hline \multirow[t]{3}{*}{ Factors } & \multicolumn{10}{|c|}{ Extent } \\
\hline & \multicolumn{2}{|c|}{ 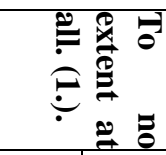 } & \multicolumn{2}{|c|}{ 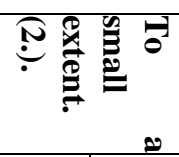 } & \multicolumn{2}{|c|}{ 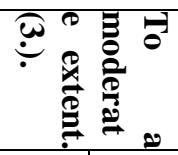 } & \multicolumn{2}{|c|}{ 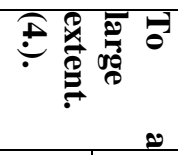 } & \multicolumn{2}{|c|}{ 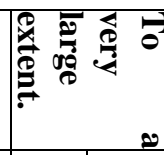 } \\
\hline & $\mathrm{f}$ & $\%$ & $\mathrm{~F}$ & $\%$ & $\mathrm{~F}$ & $\%$ & $\mathrm{~F}$ & $\%$ & $\mathrm{~F}$ & $\%$ \\
\hline $\begin{array}{l}\text { a. Cultural dietary rules and } \\
\text { requirements. }\end{array}$ & 125 & 33.3 & 114 & 30.4 & 77 & 20.5 & 44 & 11.7 & 15 & 4.0 \\
\hline b. Food composition. & 52 & 39.9 & 123 & 32.8 & 120 & 32.0 & 60 & 16 & 20 & 5.3 \\
\hline Ethnic identity. & 47 & 12.5 & 75 & 20 & 149 & 39.7 & 79 & 21.1 & 25 & 6.7 \\
\hline d. $\quad$ Lifestyle. & 36 & 9.6 & 79 & 21.1 & 125 & 33.3 & 101 & 26.9 & 34 & 9.1 \\
\hline Religious dietary requirements & 47 & 12.5 & 58 & 15.5 & 112 & 29.9 & 111 & 29.6 & 47 & 12.5 \\
\hline Nature of the food item. & 33 & 8.8 & 69 & 18.4 & 110 & 29.3 & 103 & 27.5 & 60 & 16 \\
\hline $\begin{array}{ll}\text { g. } & \text { Nutritional requirements. }\end{array}$ & 32 & 8.5 & 57 & 15.2 & 111 & 29.6 & 93 & 24.8 & 82 & 21.9 \\
\hline
\end{tabular}

In reference to the response from supervisory staff, majority of respondents were found to prefer food items prepared and served in their native ways. (Gill, et al, 2008.), for example "Nyuka", "aliya", "rech" among others in Taj Super food, Green garden restaurant, Tilapia beach, the Bistro restaurant and Splash Food service. Consequently, majority of the respondents indicated that traditions are a key factor in their food choices, and thus they were found to prefer food items prepared and served in the native traditional way.

In comparison to a similar research carried out in America, (Kamunyika, 2014), the study is in agreement with the findings that dietary choices of people of various ethnic groups continue to be influenced by traditional food practices and/ or religious customs.

\subsubsection{Taboos of Respondents}

Respondents were asked to indicate whether they strongly disagree, disagree, agree or strongly agree, in relation to the variables under taboos determining their food choices. Using a Likert scale, the results were presented in table 3.6. The results show that $53.6 \%$ of the respondents agree that cultural dietary rules and regulations determine food choice, $52.8 \%$ agree that religious dietary restrictions determine food choice and $41.6 \%$ agree that positive cultural attitude towards the food item determine food choice.

Table3.6. Likert scale on taboos in relation to food choices

\begin{tabular}{|c|c|c|c|c|c|c|c|c|}
\hline \multirow[t]{2}{*}{ Variables } & \multicolumn{2}{|c|}{ 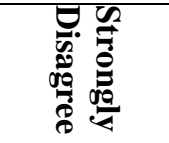 } & \multicolumn{2}{|c|}{ 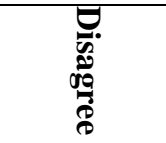 } & \multicolumn{2}{|c|}{ 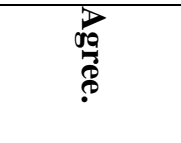 } & \multicolumn{2}{|c|}{ 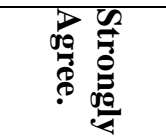 } \\
\hline & $\mathbf{F}$ & $\%$ & $\mathbf{f}$ & $\%$ & $\mathbf{f}$ & $\%$ & $\mathbf{F}$ & $\%$ \\
\hline a. $\quad$ Religious dietary restrictions. & 74 & 19.7 & 66 & 17.6 & 198 & 52.8 & 37 & 9.9 \\
\hline b. Cultural dietary rules and regulations. & 23 & 6.1 & 94 & 25.1 & 201 & 53.6 & 57 & 15.2 \\
\hline $\begin{array}{l}\text { c. Positive cultural attitude towards the food } \\
\text { item. }\end{array}$ & 26 & 6.9 & 63 & 16.8 & 156 & 41.6 & 130 & 34.7 \\
\hline $\begin{array}{l}\text { d. Culturally acceptable food preparation, } \\
\text { handling and service methods. }\end{array}$ & 26 & 6.9 & 74 & 19.7 & 136 & 36.3 & 139 & 37.1 \\
\hline $\begin{array}{l}\text { e. Acceptable ingredients in the preparation of } \\
\text { the food item. }\end{array}$ & 30 & 8.0 & 82 & 21.9 & 150 & 40.0 & 113 & 30.1 \\
\hline $\begin{array}{l}\text { f. Acceptable personnel in handling and service } \\
\text { of the food item. }\end{array}$ & 37 & 9.9 & 90 & 24.0 & 137 & 36.5 & 111 & 29.6 \\
\hline $\begin{array}{l}\text { g. Stage of growth and development in regulating } \\
\text { consumption of the food. }\end{array}$ & 43 & 11.5 & 76 & 20.3 & 138 & 36.8 & 118 & 31.5 \\
\hline
\end{tabular}


However, $24 \%$ of the respondents disagree that acceptable personnel in handling and service of food item determine food choice, $20.3 \%$ disagree that stage of growth and development determine food choice, and $21.9 \%$ disagree that acceptable ingredients in preparation and service of food item determine food choice. Thus from the results, the study shows that over sixty percent of respondents agree that taboos determine food choices, hence certain prohibitions on food choices play a big role in determining food choices among hospitality clientele as argued out by Reisch (2013), and thus in agreement with the results of this study.

Responses from supervisory staff indicate that some respondents do not consume goat meat and fish among the Luo and Luhya communities. However, majority of the responses from Haandi Restaurant indicated that respondents do not consume beef; while on the other hand, some responses from Taj super food, Green Garden Restaurant, Splash food service, and Mahfudh Restaurant indicated it was not allowed culturally for children to consume eggs, women are prohibited from consuming gizzards and Muslims were only allowed to consume "halal" food. This is in agreement with what is argued out by Guide to Modern meals, second Canadian Edition (1982) that food superstitions and taboos, which forbid eating certain foods because of cultural traditions, are common in many cultures across the world.

\subsubsection{Beliefs of Respondents}

Respondents were asked to select the most important and the least important factors that determine their food choices. The frequencies of the results are as presented in table 3.7. The results show that $59.7 \%$ of the respondents indicated that customary beliefs associated with the food item is the most important factor that influences food choices, $55.7 \%$ indicated that beliefs on food preparation, cooking and service is the most important factor, and 55.2\% indicated that beliefs on food content is the most important factor.

Table3.7. Frequency distribution of beliefs of the respondents

\begin{tabular}{|c|c|c|c|c|}
\hline \multirow[t]{2}{*}{ FACTORS } & \multicolumn{2}{|c|}{$\begin{array}{c}\text { Most } \\
\text { important }\end{array}$} & \multicolumn{2}{|c|}{$\begin{array}{c}\text { Least } \\
\text { important }\end{array}$} \\
\hline & $\mathbf{F}$ & $\%$ & $\mathbf{F}$ & $\%$ \\
\hline $\begin{array}{l}\text { a. I would make food choices based on customary beliefs associated } \\
\text { with the food item. }\end{array}$ & 224 & 59.7 & 151 & 40.3 \\
\hline $\begin{array}{l}\text { b. I would make food choices based on special diets and healthy } \\
\text { eating beliefs. }\end{array}$ & 198 & 52.8 & 177 & 47.2 \\
\hline c. I would make food choices based on beliefs of its content. & 207 & 55.2 & 168 & 44.8 \\
\hline d. I would make food choices based on religious beliefs. & 171 & 45.6 & 204 & 54.4 \\
\hline $\begin{array}{l}\text { e. I would make food choices based on beliefs about its preparation, } \\
\text { cooking and service. }\end{array}$ & 209 & 55.7 & 166 & 44.3 \\
\hline f. I would make food choices based psychological beliefs & 144 & 38.4 & 231 & 61.6 \\
\hline g. I would make food choices based on perceptions. & 156 & 41.6 & 219 & 58.4 \\
\hline
\end{tabular}

On the other hand, $61.6 \%$ of the respondents indicated that psychological beliefs is the least important factor, 58.4\% indicated that perception is the least important factor, and 54.4\% indicated that religious beliefs is the least important factor. Thus the results show that fifty percent of respondents indicated that beliefs forms the least important factor that determines food choices. Notwithstanding, scientific beliefs are becoming more pronounced on the basis of consuming fruits and vegetables of all kinds which has been associated with a reduced risk of many lifestyle related health conditions (Heiner, 2012), and thus this might have contributed on the responses which indicated that beliefs is the most important factor in their food choices by the other fifty percent.

All the same, responses from majority of the supervisory staff show that minority of respondents indicated that beliefs is a key factor in their food choices, against the majority with a contrary opinion. In relation to the Pan-European survey of consumer attitudes to food choice in 15 European member states, $74 \%$ of respondents attributed their food choice on beliefs (Glanz \& Mullis, 2013). This may be as a result of global differences in beliefs as a determinant of food choice. 


\subsubsection{Rituals of Respondents}

Respondents were asked to indicate with either "Yes" or "NO" rituals influence their food choices. The results were presented as shown in table 3.8. From the table, the results depicts 261 respondents, with observed proportion of 0.70 make their food choices on the basis of special religious practices and 214 respondents with an observed proportion of 0.56 make their food choices on the basis of connecting with god(s). On the other hand, 331 respondents, with an observed proportion of 0.88 do not make their food choices on the basis of values, and 165 respondents, with an observed proportion of 0.57 do not make food choices on the basis of occasion. Averagely, the study shows that fifty-five percent of respondents indicated that rituals do not determine their food choices.

Table3.8. Binomial Presentation of the Variable Rituals

\begin{tabular}{|c|c|c|c|c|}
\hline Category & Variable & $\mathbf{F}$ & $\mathbf{\%}$ & Proportion. \\
\hline \multirow{2}{*}{ Special Religious Practices } & Yes & 261 & 69.6 & .70 \\
\cline { 2 - 5 } & No & 114 & 30.4 & .30 \\
\hline \multirow{2}{*}{ Occasion } & Yes & 161 & 42.9 & .43 \\
\cline { 2 - 5 } & No & 165 & 57.1 & .57 \\
\hline \multirow{2}{*}{ Connect with gods } & Yes & 214 & 56.0 & .56 \\
\cline { 2 - 5 } & No & 210 & 44.0 & .44 \\
\hline Values & Yes & 44 & 11.7 & .12 \\
\cline { 2 - 5 } & No & 331 & 88.3 & .88 \\
\hline
\end{tabular}

Consequently the responses from supervisory staff show that majority of the sampled respondents indicated that food rituals is not a key factor in their food choices. However, a few responses from respondents' highlighted that food regulations differ from one Christian denomination to another. Example quoted was the ritual of consuming unleavened bread and wine (Mathew 26: 17-30), in addition to special religious functions which are always practices by religious groups, especially on Friday during lent, thus avoidance of meat and dairy products. This could suggest that the rituals that might be observed by the respondents (45\%) may be on the basis of religion. Thus Mohsen (2011) asserts that Christianity is the mostly practiced religion in the region and Kenya at large, and thus confirming the influence of religion, and specifically Christianity on food choices.

In comparison to a study carried out by Kathleen Vohs (2013), and published in psychological science, which revealed that small rituals carried out by consumers before consuming food or drinks can alter flavor perception, with the team behind the study suggesting that while many rituals may seem small or mundane, the effects they produce are quite tangible. This might be in agreement with this study as the results show minority of respondents makes food choices on the basis of rituals, which should not be assumed.

\subsection{Hypotheses Testing}

The study sought to determine the relationship between cultural factors and food choices by hospitality clientele in commercial catering outlets within Kisumu County. In order for the researcher to obtain information on the main objective of the study, items on the questionnaire were scored according to the way they were answered by the respondents. And thus to investigate the relationship between cultural factors determining food choices and the food choices the following null hypotheses were formulated and tested;

\subsubsection{There is no Significant Relationship between Cultural Factors and Food Choices among Hospitality Clientele.}

A Chi-square test was used to find out whether there is any significant difference in the relationship between cultural factors and food choices. The null hypothesis was tested at $0.05 \%$ level of significance and the results were presented as shown in table 3.9. From the analysis, at 5\% significance level, the results shows that the p-values for the four factors (traditions, taboos, beliefs and rituals) that formed the IV are; $0.356,0.876,0.199$ and 0.661 respectively. Thus $p>0.05$ and hence the study failed to reject the null hypothesis and concludes that at $95 \%$ confidence level, there is no significant relationship between cultural factors and food choices by hospitality clientele in commercial catering outlets within Kisumu city in Kisumu County. 
The Role of Culture on Food Choices: A Case Study of Hospitality Clientele in Independent Commercial Catering Outlets

Table3.9. Relationship between cultural factors and food choices

\begin{tabular}{|l|l|l|l|}
\hline Variable & $\chi^{2}$-value & Df & p-value \\
\hline Tradition & 28.042 & 26 & 0.356 \\
\hline Taboos & 12.187 & 18 & 0.876 \\
\hline Beliefs & 12.254 & 9 & 0.199 \\
\hline Rituals & 2.407 & 4 & 0.661 \\
\hline
\end{tabular}

3.3.2. There is no Significant Influence of Environmental Factors on the Relationship between Cultural Factors and Food Choices by Hospitality Clientele.

Regression analysis was used to find out whether there is significant influence of environment factors on the relationship between cultural factors and food choices among the hospitality clientele in independent commercial catering outlets within Kisumu County. The null hypothesis was tested at $0.05 \%$ level of significance and the results were presented in table 3.10. The model summary provides the correlation coefficient and coefficient of determination $\left(\mathrm{r}^{2}\right)$ for the regression model. The coefficient of 0.071 suggests there is a weak positive influence of environmental factors on the relationship between cultural factors and food choices.

Table3.10. Regression Model Summary

\begin{tabular}{|l|r|r|r|r|}
\hline Model & $\mathrm{R}$ & R Square & Adjusted R Square & Std. Error of the Estimate \\
\hline 1 & $.071^{\mathrm{a}}$ & .005 & .000 & .635 \\
\hline
\end{tabular}

a. Predictors: (Constant), environmental factors, cultural factors

b. Dependent variable: Food choices

Table3.10. ANOVA

\begin{tabular}{|l|l|r|r|r|r|r|}
\hline Model & Sum of Squares & Df & Mean Square & F & Sig. \\
\hline 1 & Regression & .767 & 2 & .383 & .951 & $.387^{b}$ \\
\cline { 2 - 7 } & Residual & 149.990 & 372 & .403 & & \\
\cline { 2 - 7 } & Total & 150.757 & 374 & & \\
\hline
\end{tabular}

Table3.10. Regression Analysis

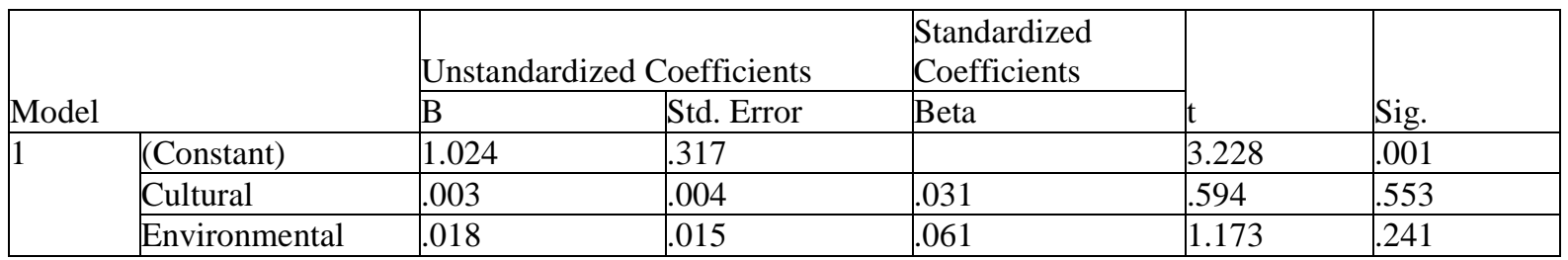

a. Dependent Variable: Food choices

The ANOVA shows whether the regression model explains a statistically significant proportion of the variance. Specifically it uses a ratio to compare how well the linear regression model predicts the outcome to how accurate simply using the mean of the outcome data as an estimate is. From the analysis, the model predicts the outcome, and thus given the weakness of the correlation the model is not statistically significant $(\mathrm{p}=.387>0.05)$.

The Regression Analysis table gives the values for the regression line. In the cultural factors row and environmental factors in the (B) column provides the gradient of the regression line which is the regression coefficient (B). This means that for every cultural factor, the model predicts an increase of 0.003 on food choice and for every environmental factor; the model predicts an increase of 0.018 on food choice. To test whether the model is statistically significant, the t-test is used. From the analysis, the study failed to reject the null hypothesis and concludes that at $95 \%$ confidence level, there is no significant influence of environmental factors on the relationship between cultural factors and food choices by hospitality clientele in commercial catering outlets within Kisumu County.

\section{CONClusion}

Basing on the results of the study, majority of the respondents indicated that there is a relationship between cultural factors and food choices by hospitality clientele in independent commercial catering 
outlets within Kisumu County. This therefore shows that food choices are determined by the cultural factors; traditions, taboos, beliefs and rituals respectively. On the other hand, the study results depicts that there is influence of environmental factors on the relationship between cultural factors and food choices by hospitality clientele in independent commercial catering outlets within Kisumu County. This implies environmental factors, including geographic factors, economic factors and social factors, have a moderating influence on the food choices by hospitality clientele.

\section{RECOMmENDATIONS FOR POLICY/PRACTICE}

The results from the study show that cultural factors determine food choices by hospitality clientele in commercial catering outlets in Kisumu City. Thus basing on the results of the study, hospitality professionals should factor in the cultural element during menu planning to strike a balance between the catering policy, the financial policy as well as the marketing policy. Accordingly, culinary training institutions within the country should embrace culture in their training programs so as to equip future hospitality personnel with diverse cultural knowledge, and therefore capable of meeting the hospitality clienteles' diverse cultural market needs.

\section{REFERENCES}

[1] Cardan, L. (2015). Origins and evolutions of the western diets; Health Implications for the 21st Century.

[2] Carlson A, Frazao E. (2012). Are Healthy Food really Expensive? It depends on how you Measure the Price. Washington DC: National Academic Press.

[3] Cannors M Margaret, J. S. (2014). Sandwiching it in: Spillover of work on to Food Choices and Family Roles in low-and moderate-income urban households. Social Science and Medicine.

[4] Davies B, Lockwood A, Ioannis, P, \& Alcott, P. (2008). Food and Beverage Management, 4th Ed. London: Hodder Education.

[5] Eric R, Alan Z, Shankar M \& Christine S. (2008). Cross-sectional Versus Longitudinal Survey Research: Concepts, Findings and Guidelines. Journal of Marketing Research , 261-272

[6] Elbert, C. (2011). Gastronomy and Cultural Heritage in a Pluralistic Society: Faith and Heritage. Retrieved January 9th 2014 from; http://faithandheritage.com/.

[7] Foskett D, \& Patricia P. (2011).The theory of hospitality and catering, 12th Edition. Book power; Hodder Education.

[8] Foskett, D, Cousins, J, \& Cailein, G. (1995). Food and Beverage Management, 2nd Ed. London: Pearson Education.

[9] Gill, P., Stewart, K., Treasure, E., \& Chadwick, B. (22nd March 2008). Methods of Data Collection in Qualitative Research; Interviews and Focus groups. British Dental journal.

[10] Glanz K, \&. Mullis. (2013). A review of Models programs, and Evidence Health Education. Environmental Interventions to promote Healthy Eating.

[11] Gordon. (2014). Food Taboos Around the World. Restaurants.

[12] Guide to Modern Meals, Second Canadian Edition. (1982). Toronto, Montreal: Mc Grow- Hill Ryerson Limited.

[13] Henn M, Weinstein M, \& Foard, N, (2009). A critical introduction to social research; 2nd Ed, SAGE Publication.

[14] Heiner B. (2012). Critical Review: Vegetables and Fruits in the Prevention of Chronic Diseases. European Journal of Nutrition.

[15] Helen S, A. (2015). Urban Development Goals (UDGs); Targets and Indicators: The Case of Kisumu. Nairobi: Government Publishers

[16] Holy Bible: New International Version. (2005). International Bible Society.

[17] Kamunyika G, (2014). Racial and Ethnic Issues in Diet and Cancer Epidemiology.

[18] Kathleen D. Vohs, Y. W. (2013). Rituals Enhance Consumption. Psychological Science.

[19] Kisumu County. (2013). Retrieved October 03rd, 2015, from Kisumu City: https://en.m.wikipedia.org/wiki/kisumu_county

[20] Kothari, R. (2010). Research Methodology, 2nd Ed. New Delhi: New Age International (P) LTD Publishers.

[21] Lamb, L. (03rd June 2015). How Culture Affects Diet. Livestrong.com.

[22] Lillicrap, D., \& Cousins, J. (2010). Food and Beverage Service, 8th Ed. London: Hodder Education. 
The Role of Culture on Food Choices: A Case Study of Hospitality Clientele in Independent Commercial Catering Outlets

[23] Mugenda, A. G. (2008). Social Science Research; Theory and Principles. Nairobi: ACTS Press.

[24] Mohsen T. (2011). Making Sense of Cronchbach's alpha. International Jounal of Medical Education , 2:53-55

[25] Sims, F. (May, 11th 2012). Ethnic Food-Love of the New. Caterer and Hotel Keeper. Retrieved January 12th 2014 from; http;//catererandhotelkeeper.co.uk/landing-pages/.

[26] Stuart, M. (2008, December 18th). Cultural gastronomy: Entertainment planet. Retrieved January 11th 2014 from; http://www.entertainmentplanet.org/.

[27] Wales, M.E. (2009). Understanding the Role of Convenience in Consumer Food Choices, Vol.2, No.2.

[28] Wessel A, \& Brien, D. (2010). Re-writing the menu: The Cultural Dynamics of Contemporary food Choices. Journal of writing and Writing Courses, Special Issue 9.

Citation: Mr. Simon Were, Okwachi et al. "The Role of Culture on Food Choices: A Case Study of Hospitality Clientele in Independent Commercial Catering Outlets." International Journal of Research in Tourism and Hospitality (IJRTH), vol 3, no. 4, 2017, pp. 44-53. doi:http://dx.doi.org/10.20431/24550043.0304005.

Copyright: (c) 2017 Authors. This is an open-access article distributed under the terms of the Creative Commons Attribution License, which permits unrestricted use, distribution, and reproduction in any medium, provided the original author and source are credited. 